\title{
Corrosion evaluation and prevention of reactor materials to contain thermochemical material for thermal energy storage
}

\author{
Aran Solé ${ }^{1}$, Camila Barreneche ${ }^{1,2}$, Ingrid Martorell ${ }^{1,3}$, Luisa F. Cabeza ${ }^{1, *}$ \\ ${ }^{1}$ GREA Innovació Concurrent, Universitat de Lleida, Lleida, Spain. Edifici CREA, Pere de Cabrera s/n, 25001, Lleida, \\ Spain. Tel.: +34-973 003576; Fax: +34-973 003575. *Icabeza@diei.udl.cat \\ ${ }^{2}$ Department of Materials Science \& Metallurgical Engineering, Universitat de Barcelona, Martí i Franqués 1-11, 08028 \\ Barcelona, Spain \\ ${ }^{3}$ Serra Húnter Fellow \\ *Corresponding author: Icabeza@diei.udl.cat
}

\section{Abstract}

Thermochemical materials (TCM) can be used for seasonal heat storage, storing high amounts of thermal energy coming from the sun in summer and releasing it in winter, when heating for houses is needed. One promising TCM for building comfort applications is the $\mathrm{Na}_{2} \mathrm{~S} /$ water pair due to its high energy density and appropriate reaction temperature that can be achieved by a solar collector. Nonetheless, $\mathrm{Na}_{2} \mathrm{~S}$ reacts with oxygen and is corrosive to metals, especially with those used to build up heat exchangers or reactors that contain the TCM. Therefore, corrosion tests in a self-developed experimental setup under vacuum conditions, 13 mbar, between $\mathrm{Na}_{2} \mathrm{~S} \cdot 9 \mathrm{H}_{2} \mathrm{O} / 5 \mathrm{H}_{2} \mathrm{O}$ and two reactor metals: copper and stainless steel 316 have been performed. Since copper is corroded and is highly used for thermochemical reactors, two promising coatings, Halar and electroless nickel, have been applied. Furthermore, aluminium has also been tested coated with these coatings. Halar is a potential candidate to protect both copper and aluminium heat exchangers/reactor that may contain $\mathrm{Na}_{2} \mathrm{~S} / \mathrm{H}_{2} \mathrm{O}$ pair for thermochemical energy storage. Stainless steel 316 is also corrosion resistant to the selected TCM.

Keywords: Corrosion; Thermal energy storage (TES); Thermochemical material (TCM); Sodium sulphide; Vacuum reactor; Coatings. 
Thermal energy storage (TES) is extremely necessary to match the energy available and the demand. This could lead to thermally independent houses, which would have a positive effect in reducing the global $\mathrm{CO}_{2}$ emissions. The research in this field is mainly focused on the storage medium and how to implement it in the most efficient way. Several storage materials have been studied, based on different concepts. Sensible, phase change and thermochemical materials are being used to fulfil energy storage requirements depending on the application [1, 2]. In this paper the focus is on thermochemical materials (TCM) which undergo a chemical reversible reaction to store and release energy. TCM is an emerging energy storage media with the potential for high-density leading to compact thermal energy storage systems [3] and for high energy efficient systems for energy conversion [4]. Moreover, those materials present a huge advantage which remains in almost zero thermal losses to the ambient, since the energy is stored in the form of chemical bonds. Therefore, TCM are suitable for seasonal storage, meaning to provide heat in winter that has been charged in summer. On the other hand, one of the major drawbacks of TCM is that they are corrosive to the reactor/heat exchanger material, usually metal based.

Corrosion causes big investment costs, results of one study show that the total annual estimated direct cost of corrosion in the U.S. is a staggering $\$ 276$ billion, approximately $3.1 \%$ of the nation's Gross Domestic Product (GDP) [5]. Hence, corrosion tests should be performed before to ensure long term performance of the equipment containing 54 TCM $[6,7]$.

In a previous study [7] results coming from an experimental corrosion test simulating an open TCM reactor between several TCM and common vessel metals were published. TCM reactors can be open or closed, integrated or non-integrated [8]. Open reactors take the water vapour from the atmospheric air while closed reactors imply that water circulates in a closed loop and is taken from an evaporator and released to a condenser. The later ones can operate under lower or vacuum pressures or inert atmospheres.

Some of the most studied TCM work better under low pressures [9] or in an inert or vacuum atmosphere when side reactions have to be controlled [10]. No literature has been found concerning corrosion vacuum tests with TCM. One of the moving forward- 
perform tests seeking for compatible materials and/or preventive solutions like applying coatings $[11,12]$.

There are several types of coating that can protect almost all metals available for engineering use from air, water, acid corrosion, saline ambient, etc. [13]. Those coating are mainly classified as organic [14] and inorganic coatings [15] and the method used to coat the substrates is the main issue under study at this moment.

The aim of this study is to develop a device to test corrosion between TCM and metals, under vacuum and controlled temperature. Moreover, experimental corrosion tests have been performed in this setup looking for the suitable material to build up vessels or reactors which contain $\mathrm{Na}_{2} \mathrm{~S} / \mathrm{H}_{2} \mathrm{O}$ pair as a thermochemical energy storage material.

From the recent literature published in this field $[1,3,7,8,12]$ it can be withdrawn the need of more research in order to overcome TCM issues like corrosion, compaction, stability, etc. to promote this technology towards market availability. The contribution of the present study is essential for the design of a reactor/heat exchanger where a TCM reaction for building applications takes place. Although it has been focused on a specific working pair, the designed methodology and setup address a specific step in the reactor design procedure when selecting metals to work in contact with TCM.

\section{Setup and methodology}

\subsection{Setup}

The present setup is designed and built to perform corrosion tests simulating closed and integrated TCM reactors. Glass has been selected for being an inert material able to stand high temperatures, low pressures, and allowing direct visual inspection. The design was thought to obtain a versatile, multifunctional device which can operate under a wide range of pressures, temperatures, and different atmospheres, therefore several TCM.

A general view of the setup is shown in Figure 1. It consists of a $5 \mathrm{~L}$ glass jacketed reactor, connected to a heating unit (thermostatic water bath), an evaporator (roundbottom flask), and a vacuum pump from Vacuubrand PC 600 series. Tubing from the reactor to the vacuum pump is polyamide based connected with common clamps. The reactor contains one open $300 \mathrm{ml}$ vessel to place the TCM and the specimens to be tested (see Figure 2). One temperature sensor is giving the TCM temperature, and another is placed in the atmosphere. Relative humidity $(\mathrm{RH})$ is also measured on-line 
L01 with a HygroPalm HP22-A. Furthermore, total pressure is measured and controlled by 102 the vacuum pump.

105 The vacuum pump runs in continuous mode, to assure vacuum inside the reactor. The 106 vacuum pump presents an outlet for venting gases, which is directed to the fume hood, 107 being cooled previously (cooling unit) to collect condensed outlet water vapour and 108 other condensable gases.

106

107
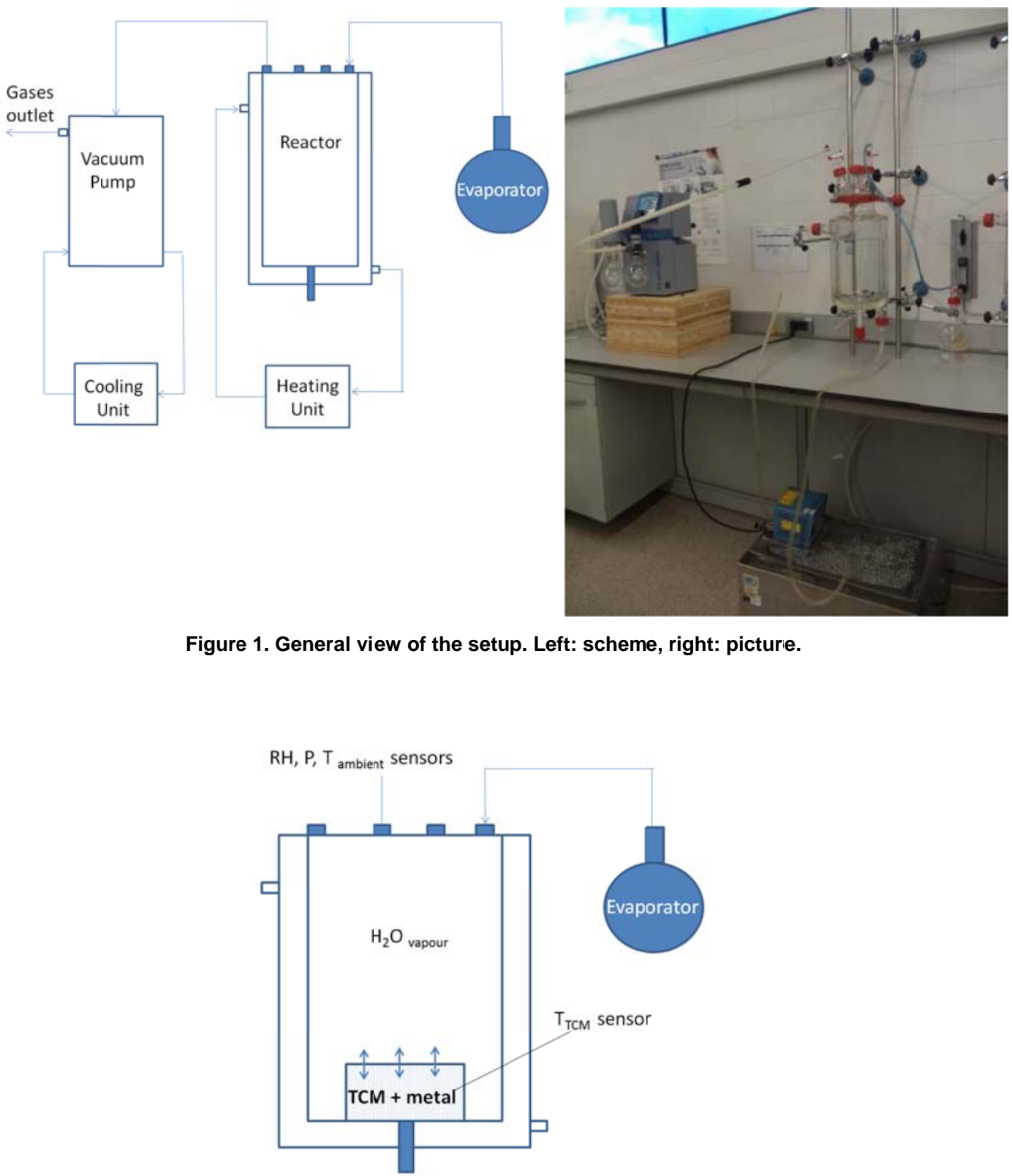
114 For each metal sample, four specimens are needed. One is the reference and the other 115 three are tested for a week in contact with the TCM. The three specimens are 116 replicates in order to ensure the repeatability of the experiments.

117 To evaluate the results, a methodology accordingly to the setup has been designed. 118 Two different methodologies, one for the single metal specimen and one for the coated 119 metals, are detailed here. First, the metal specimen are cleaned (no polished, no 120 brushed, only acetone). Then, they are weighted in a precision balance $( \pm 0.01 \mathrm{mg})$ 121 AG135 from Mettler-Toledo and are visually observed by a Zwek optical microscope. 122 The coated specimen are weighted in the same precision balance, but observed in an 123 ESEM Quanta $200 \mathrm{FEI}$, XTE 325/D8395 scanning electronic microscope (SEM). An 124 SEM is needed for the coated samples since more precision and resolution is required 125 to measure the coating thickness. At this point the methodology merges and three 126 specimens of each sample are placed inside the reactor in a $300 \mathrm{ml}$ vessel fully in 127 contact with the solid $\mathrm{Na}_{2} \mathrm{~S} \cdot 9 \mathrm{H}_{2} \mathrm{O}$. An immersion corrosion test following ASTM G1 [16], 128 under the specified operating conditions determined by the TCM selected, is performed 129 for a week. Before vacuum the reactor, nitrogen gas flows through it to make sure there 130 is no oxygen inside. Finally, the heating unit is connected and set to the established set 131 point.

After the corrosion test, the three specimens are visually inspected, weighted in the same balance and observed in the appropriate microscope. Corrosion processes that go further than the surface level can be identified by both microscopes. Therefore, vessel materials that are not appropriate can be identified. Also, TCM characterization after corrosion tests should be performed (i.e. XRD) to identify the reaction process of the TCM and other possible chemicals.

On the other hand, previous tests were performed to ensure vacuum tightness in the reactor and to check the start-up of the reactor as well as to conduct it to established steady state conditions. Then, tests with only TCM have to be conducted to see the behaviour of the TCM without possible products from corrosion reaction.

The methodology to evaluate corrosion is based on ASTM G1. Corrosion rates are obtained using equation 1 for single metals since ASTM G1 is not adapted to coated metals. Mass loss corresponds to the decrease in mass between before and after (after chemical cleaning, see ASTM G1) the corrosion test. 


$$
C R=\frac{\Delta m}{A \cdot\left(t_{o}-t_{f}\right)}
$$

147 Corrosion rate $\mathrm{CR}\left(\mathrm{mg} / \mathrm{cm}^{2} \cdot \mathrm{yr}\right)$ takes into account the mass loss $(\Delta \mathrm{m})$, the contact area 148 of the metal specimen $(A)$, and the time of exposure $\left(t_{0}-t_{f}\right)$.

\section{Materials}

\subsection{TCM}

152

A promising TCM, mainly seeking high energy density, has been selected to test and validate the new experimental setup. Sodium sulphide and water pair $\left(\mathrm{Na}_{2} \mathrm{~S} / \mathrm{H}_{2} \mathrm{O}\right)$ as a TCM presents a net energy storage value (see Table 1) which is within the best salt hydrates for building applications [17, 18]. Its main drawbacks according to the hazard statements of the Regulation (Ec) 1272/2008 are: toxic if swallowed, it may be corrosive to metals, and in contact with acids liberates toxic gas $\left(\mathrm{H}_{2} \mathrm{~S}\right)$ [19]. Swallowing it can be avoided if the material is kept in a closed vessel as the one designed here. Corrosion can be prevented by coating the metal in contact as it is done in this work. Furthermore, an inert atmosphere or vacuum is needed to prevent sulphites formation and this is why the experimental setup is designed to work under vacuum conditions.

The purchased sodium sulphide nonahydrate $\left(\mathrm{Na}_{2} \mathrm{~S} \cdot 9 \mathrm{H}_{2} \mathrm{O}\right)$ is manufactured by Alfa Aesar with $98.0 \%$ purity. Properties associated to the chosen TCM reaction are shown in Table 1.

The reaction from nonahydate to pentahydrate accomplishes the requirement for building applications, a reaction temperature below $100-150{ }^{\circ} \mathrm{C}$ achievable by solar collectors and promising net enthalpy values, as shown in Table 1.

Table 1. TCM reaction properties for the corrosion vacuum tests.

\begin{tabular}{|l|l|l|l|}
\hline $\mathrm{Na}_{2} \mathrm{~S} \cdot 9 \mathrm{H}_{2} \mathrm{O}(\mathrm{s}) \rightarrow \mathrm{Na}_{2} \mathrm{~S} \cdot 5 \mathrm{H}_{2} \mathrm{O}(\mathrm{s})+4 \mathrm{H}_{2} \mathrm{O}(\mathrm{v})$ & nonahydrate & pentahydrate & Ref \\
\hline $\mathrm{CAS}$ number & $1313-84-4$ & $1313-83-3$ & {$[19]$} \\
\hline Density $\left(\mathrm{g} / \mathrm{cm}^{3}\right)$ & 1.43 & 1.58 & {$[17]$} \\
\hline Melting temperature $\left({ }^{\circ} \mathrm{C}\right)$ & 49 & 83 & {$[17,20]$} \\
\hline Molecular weight $(\mathrm{g} / \mathrm{mol})$ & 240.184 & 168.122 & {$[21]$} \\
\hline
\end{tabular}




\begin{tabular}{|l|l|l|}
\hline Extrapolated onset temperature $\left({ }^{\circ} \mathrm{C}\right)$ & 32.5 & {$[20]$} \\
\hline$\Delta \mathrm{H}_{\mathrm{r}}\left(\mathrm{KJmol}{ }^{-1}\right)$ & $215 \pm 20$ & {$[20]$} \\
\hline$\Delta \mathrm{H}_{\mathrm{net}, \mathrm{V}^{\star}}\left(\mathrm{KWhm}^{-3}\right)$ & 133 & {$[17]$} \\
\hline
\end{tabular}

172

173 The reactor operating conditions, which are given by the TCM reaction itself [20], are shown in Table 2. Everything runs in continuous mode. Water vapour pressure is always as expected since it is taken from the external evaporator, which is also under vacuum. Water vapour pressure is also checked by measuring $\mathrm{RH}$ and calculating saturated pressure by Clausius-Clapeyron equation.

9

Table 2. Reactor test operating conditions.

\begin{tabular}{|l|l|}
\hline Water vapour pressure (mbar) & 13 \\
\hline Reactor temperature $\left({ }^{\circ} \mathrm{C}\right)$ & 32.5 (dehydration) \\
\hline Evaporator temperature $\left({ }^{\circ} \mathrm{C}\right)$ & 10 \\
\hline
\end{tabular}

\subsection{Metals and coated metals}

The absorption and release of energy coming from the TCM reaction takes place in reactors. Therefore, heat transfer is needed to be promoted from the TCM to the heat transfer fluid, usually water for building applications. In that sense prototypes are being made of high conductivity metals, such as: copper, aluminium, or even stainless steel 316.

It is known that there are several materials to be avoided in contact with $\mathrm{Na}_{2} \mathrm{~S}$ : acids, oxidizing agents, water/moisture, aluminium/aluminium alloys, copper and air [22].

In this paper single metals under study are stainless steel 316 and copper. Moreover, coatings are considered to protect copper and aluminium from $\mathrm{Na}_{2} \mathrm{~S}$ corrosion. Two different coatings were chosen, halar (organic coating) and electroless nickel (inorganic coating). All the pieces dimensions are $6 \times 6 \times 0.2 \mathrm{~cm}$.

Halar ${ }^{\circledR}$ is an organic coating which is mainly composed by Ethylene Chloro Trifluoroethylene (ECTFE). At temperatures up to $120{ }^{\circ} \mathrm{C}$ the polymer is 
neither affected by stress cracking nor attacked by the majority of chemical reagents. ECTFE is resistant to most chemicals except chlorinated solvents and has better barrier properties to $\mathrm{SO}_{2}, \mathrm{Cl}_{2}, \mathrm{HCl}$, and water than fluorinated ethylene propylene (FEP) and polyvinylidene fluoride (PVDF) [23]. These coatings can be applied with electrostatic powder coating or with spray coating in the slurry formulation which have been described by Choy [24].

Electroless autocatalytic Nickel-Phosphorus Coatings, from now on electroless nickel, are alloys of nickel and phosphorus produced by autocatalytic chemical reduction with hypophosphite and generally deposited from acid solutions operating at high temperatures. These coatings have multifunctional properties, such as hardness, heat hardenability, abrasion, wear and corrosion resistance, magnetics, electrical conductivity provides diffusion barrier, and solderability [25]. A finishing based on an anticorrosive spray has also been applied onto one copper sample to see if it acts as a protective film against $\mathrm{Na}_{2} \mathrm{~S}$.

\section{Results and discussion}

Obtained results from the corrosion test performed to the abovementioned specimen are gathered and shown by, first, single metal specimen which are copper and stainless steel 316 , and secondly, by the coated specimen.

\subsection{Metal specimen}

\section{A) Copper}

Corrosion signs were clearly observed in copper specimens, as it can be seen in Figure 3. Black spots (i.e. CuS or/and $\mathrm{Cu}_{2} \mathrm{~S}$ ) on the surface which are products from a side reaction can be clearly observed. The three last pictures (Figure 3, bottom) are from the same specimens after chemical cleaning (following ASTM G1). They present no solid products from corrosion process, but still some surface damage is seen since the surface colour is deteriorated when compared to the initial copper specimen.

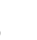

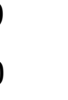



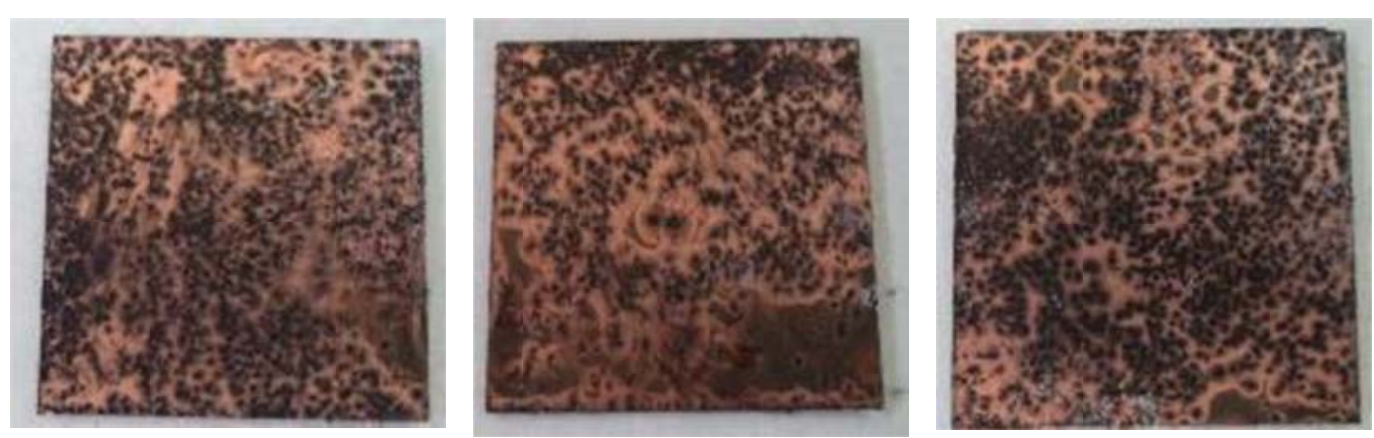

Specimen before chemical cleaning process (after corrosion test)
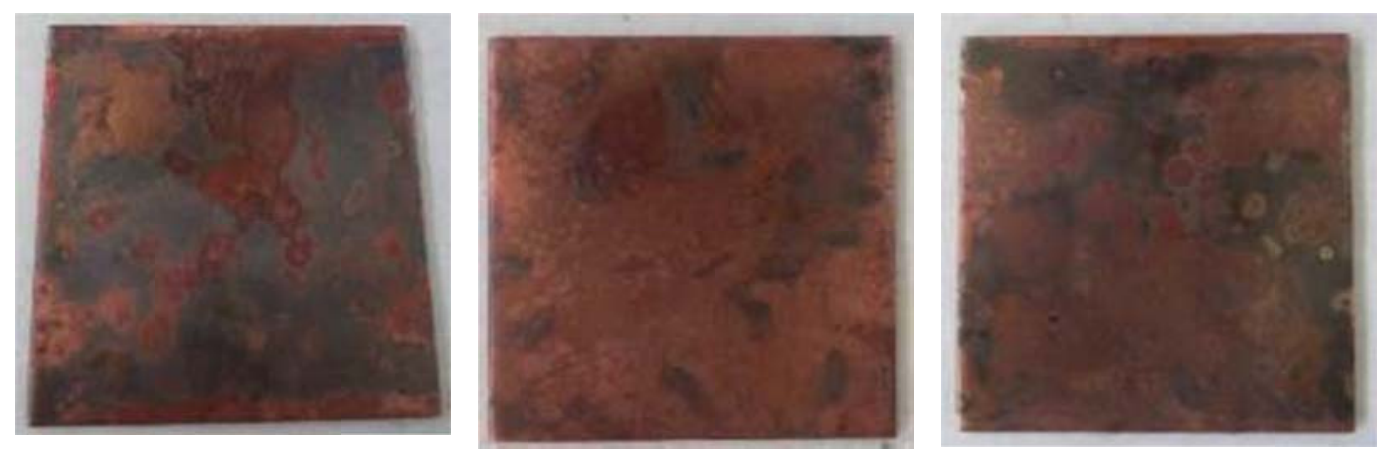

Specimen after chemical cleaning process

234

Figure 1. Copper specimen after one week corrosion test with $\mathrm{Na}_{2} \mathrm{~S}$. Top: before and bottom: after cleaning.

The microscopic section images of the specimen (Figure 4) denote there is no corrosion further than the surface. The lines are due to the cutting process of the specimen.
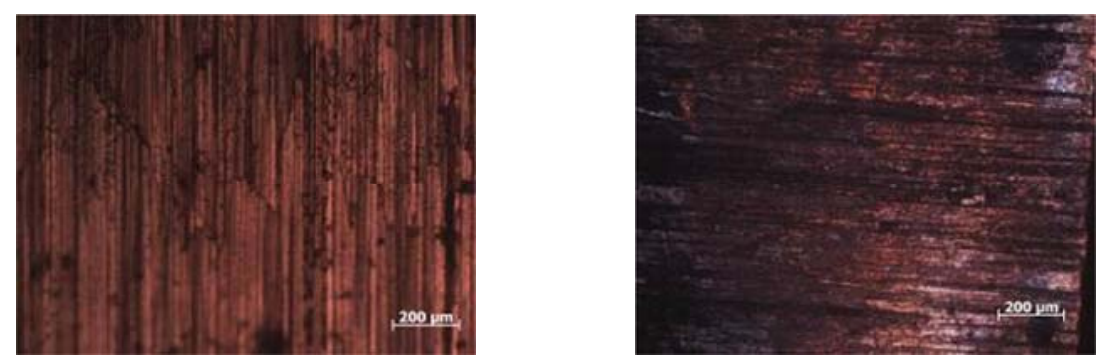

Figure 2. Copper section microscopic images before (left) and after (right) corrosion test.

Corrosion rates $(\mathrm{CR})$ are listed in Table 3. These values of $\mathrm{CR}$ belong to the not recommended range (50-99 $\mathrm{mg} \mathrm{cm}^{-2} \mathrm{yr}^{-1}$ ) for service greater than a year (see Table 4). When comparing these values with the previously obtained [7] in atmospheric pressure and humidity conditions, it can be concluded that in vacuum, CR value is reduced 
252

253

254

255

256

257

258

259

260

261

262

around 30 times. Nonetheless, for this application copper is not recommended to contain $\mathrm{Na}_{2} \mathrm{~S} / \mathrm{H}_{2} \mathrm{O}$, neither in open nor in close configurations. For that reason, it is remarkable that a coating is needed to protect it before its implementation as part of a system containing this TCM.

Table 3. Initial and final weight of the Cu specimen under study and calculated CR.

\begin{tabular}{|l|c|c|c|}
\hline & Initial weight $(\mathrm{g})$ & Final weight $(\mathrm{g})$ & $\mathrm{CR}\left(\mathrm{mg} \mathrm{cm}^{-2} \mathrm{yr}^{-1}\right)$ \\
\hline Specimen 1 & 63.694 & 63.609 & 85.54 \\
\hline Specimen 2 & 63.681 & 63.601 & 80.14 \\
\hline Specimen 3 & 63.727 & 63.646 & 81.11 \\
\hline
\end{tabular}

Table 2. Guide for corrosion weight loss used in the industry [26].

\begin{tabular}{|c|c|}
\hline $\mathrm{mg} / \mathrm{cm}^{2} \mathrm{yr}$ & Recommendation \\
\hline$>1000$ & Completely destroyed within days \\
\hline $100-999$ & Not recommended for service greater than a month \\
\hline $50-99$ & Not recommended for service greater than 1 yr \\
\hline $10-49$ & Recommended for long term service \\
\hline $0.3-9.9$ & Recommended for long term service; no corrosion, other than as a \\
\hline$<0.2$ & result of surface cleaning, was evidenced \\
\hline
\end{tabular}

\section{4}

5

\section{B) Stainless steel 316}

Stainless steel 316 did not show corrosion signs after the test. Specimens have the same appearance as before testing. There are not corrosion effects on the surface. Moreover, microscopic images (see Figure 5) show that there are not corrosion points on the surface of the specimens under study. There is no difference at microscope scale regarding the section surface of the stainless steel specimens under study, either. 

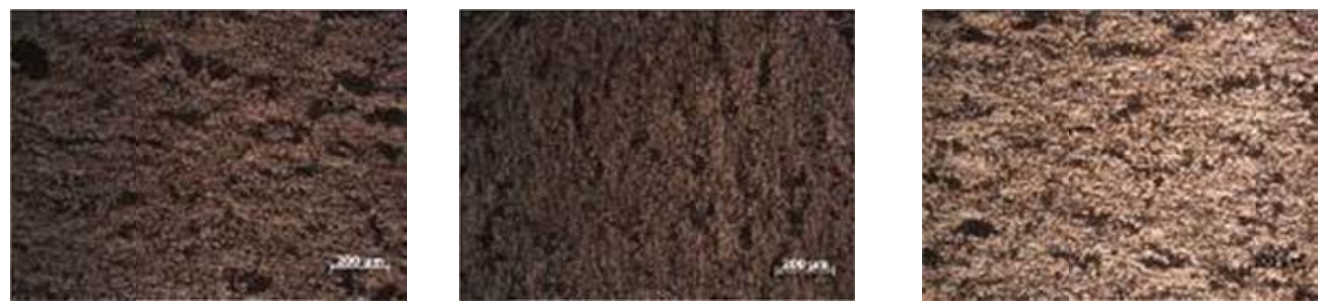

Specimens before corrosion test
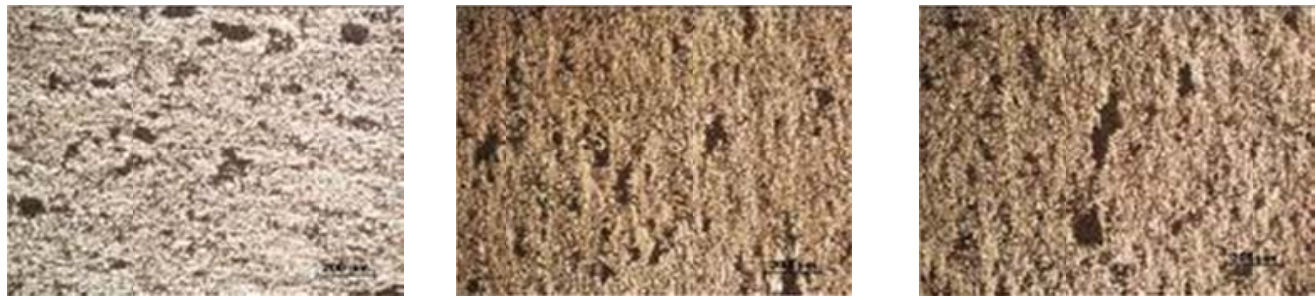

Specimens after corrosion test

266

267

267

272

273

274

275

276

273

274

275

282

283

284

285

286

287

288

Figure 5. Stainless steel 316 specimens after one week corrosion test with $\mathrm{Na}_{2} \mathrm{~S}$. Microscopic images before (top) and after (bottom) corrosion test.

Corrosion rate values are shown in Table 5, which are inside recommended range for long term service (see Table 4). CR values in this case are in the same range as the obtained under atmospheric pressure and humidity conditions [7]. Therefore, stainless steel 316 corrosion compatibility with $\mathrm{Na}_{2} \mathrm{~S} / \mathrm{H}_{2} \mathrm{O}$ is not influenced by the working atmosphere (e.g. air and vacuum).

Table 3. Initial and final weight of the stainless steel 316 specimens under study and calculated CR.

\begin{tabular}{|l|c|c|c|}
\hline & Initial weight $(\mathrm{g})$ & Final weight $(\mathrm{g})$ & $\mathrm{CR}\left(\mathrm{mg} \mathrm{cm}^{-2} \mathrm{yr}^{-1}\right)$ \\
\hline Specimen 1 & 80.804 & 80.800 & 4.34 \\
\hline Specimen 2 & 81.046 & 81.041 & 5.05 \\
\hline Specimen 3 & 80.883 & 80.878 & 4.44 \\
\hline
\end{tabular}

Stainless steel 316 is a potential candidate as it has been experimentally tested under the real operating conditions and the results recommend it for long term service; nevertheless there are also other aspects to take into account when selecting a material vessel to build up a heat exchanger or a reactor. Heat transfer should not be limiting in a TCM reactor since then thermal power output of the reactor/heat exchanger would be lower than expected. Since a coating layer represents an additional thermal resistance in the heat transfer during reaction, experiments are 
282 suggested to be carried out to reveal to which extent the thermal performance of the

283 heat exchanger is decreased by the coating.

\subsection{Coated specimens: halar® and electroless nickel}

\section{A) Copper coated with halar ${ }^{\circledR}$}

287

288

Figure 6 shows the SEM images captured for each Cu-specimen tested under vacuum corrosion test and one reference. The images correspond to the cross section of the specimens under study where the halar® coating can be seen in the upper side.

291 SEM images revealed that the coating thickness remains constant and is exactly the same (around 190-200 $\mu \mathrm{m}$ ) as it is observed in Figure 6. The coating thickness remains almost constant regardless of the specimen. Therefore, copper coated with halar® is corrosion resistant to $\mathrm{Na}_{2} \mathrm{~S} / \mathrm{H}_{2} \mathrm{O}$ pair and can be used when copper is needed as a base metal.

296

297

298

299

300

301

302

303

304

305

306

307 


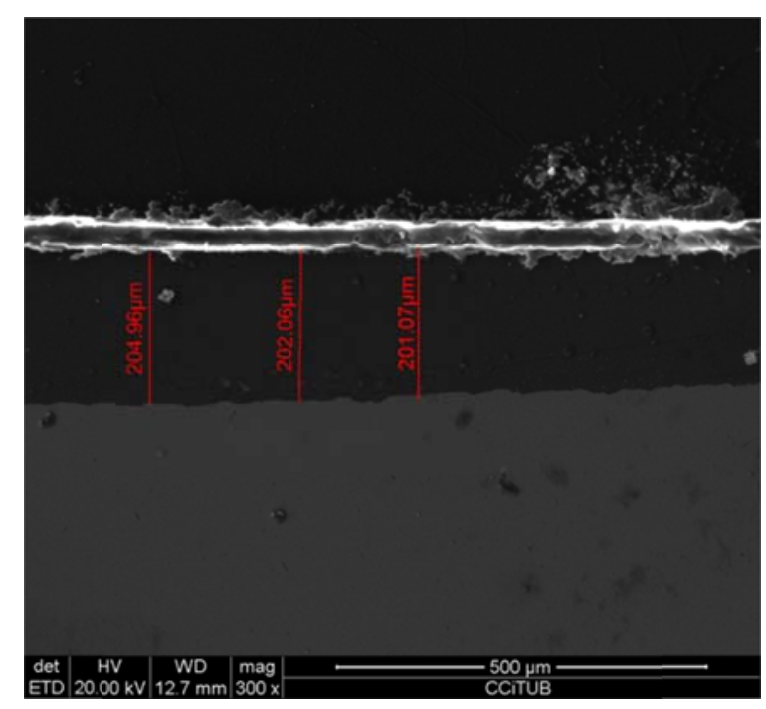

Reference

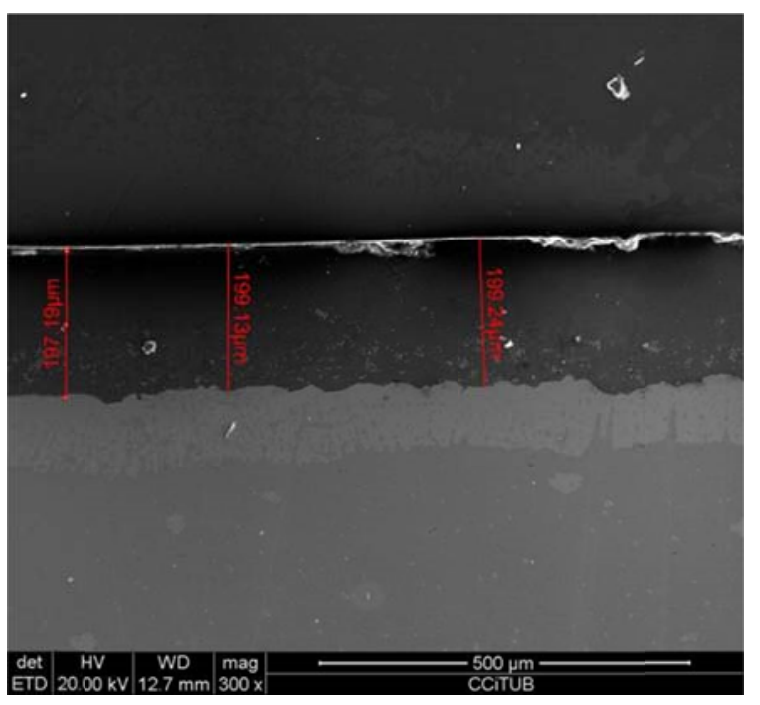

Specimen 2

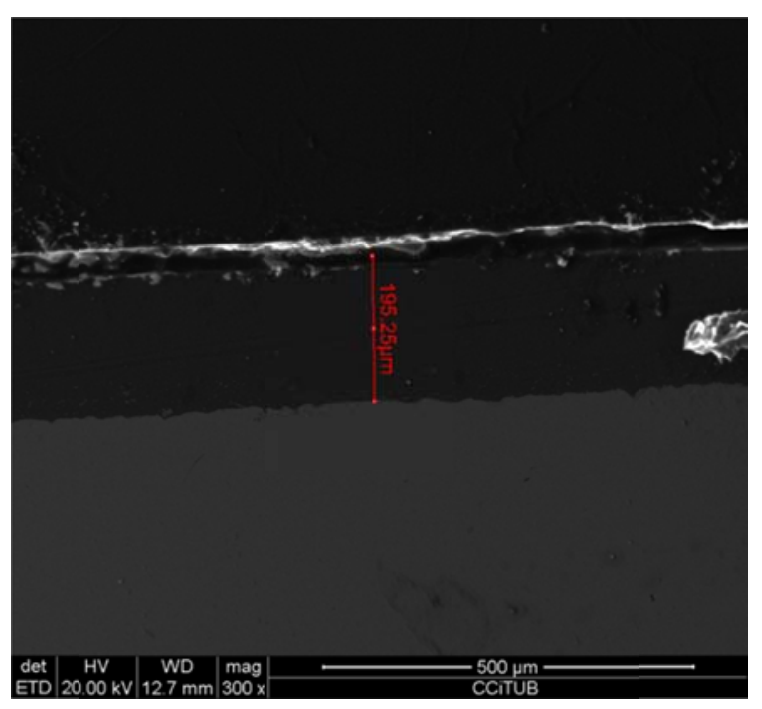

Specimen 1

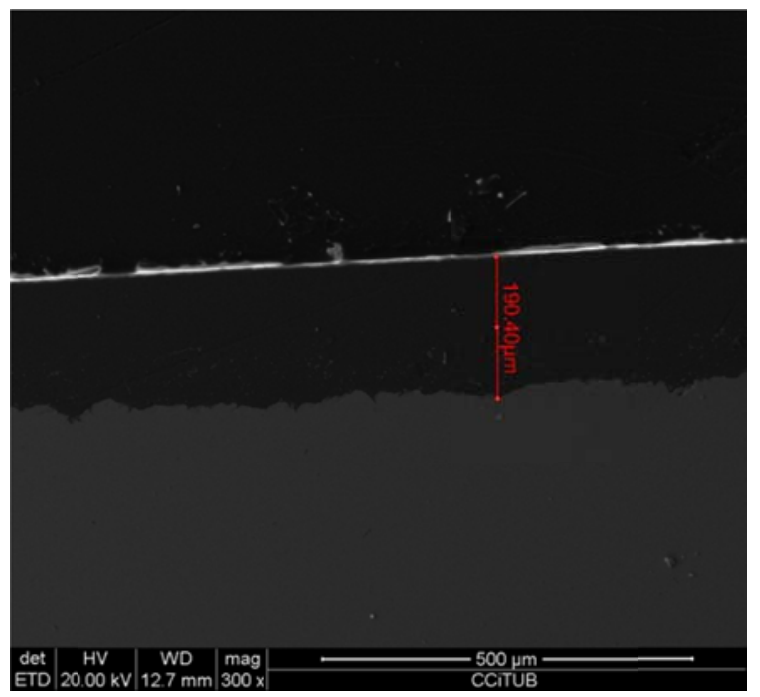

Specimen 3

Figure 6. Copper specimens coated with halar ${ }^{\circledR}$.

\section{B) Copper coated with electroless nickel}

Figure 7 shows the coating of the specimens coated with $\mathrm{Ni}$-electroless technique. There is one specimen without being tested (the reference), there are two specimens coated with $\mathrm{Ni}$-electroless coating and there is one specimen that has the same coating and also a finish anticorrosive and non-sticked spray (M3). The samples morphology is shown in the SEM using secondary electrons. However, the backscattered electrons are able to provide composition information of the displayed sample: the darker the sample the lighter the atoms are. Thus, the morphology of the Aluminium + electroless $\mathrm{Ni}$ samples is very similar and secondary electrons are unable to differentiate the sample and the coating. In addition, backscattered electrons not clarify much the difference between sample and coating because $\mathrm{Ni}$ and $\mathrm{Al}$ have very similar atomic weight. Thereby, SEM images are not very enlightening, although the thickness of the coating layer is distinguished. Figure 7 shows that there is no corrosion and the 
thickness of the coating is the same for all the specimens under study after one week of vacuum corrosion testing. Nonetheless, pictures taken at surface level, after the test, show clear damage (Figure 8), even more when this anticorrosive spray is not applied on the specimen. The spray applied is useful to avoid the oxide formation on the surface of the sample under study.

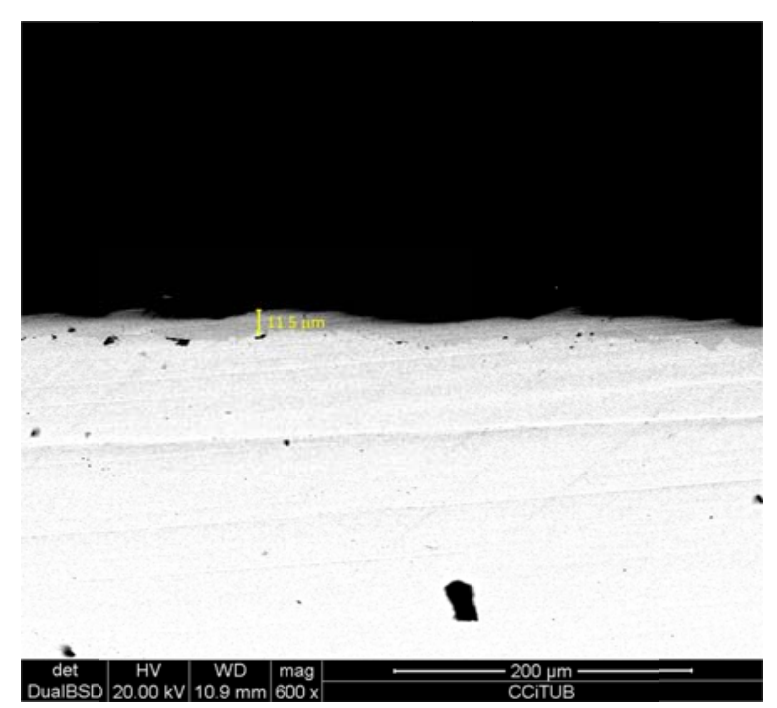

Reference

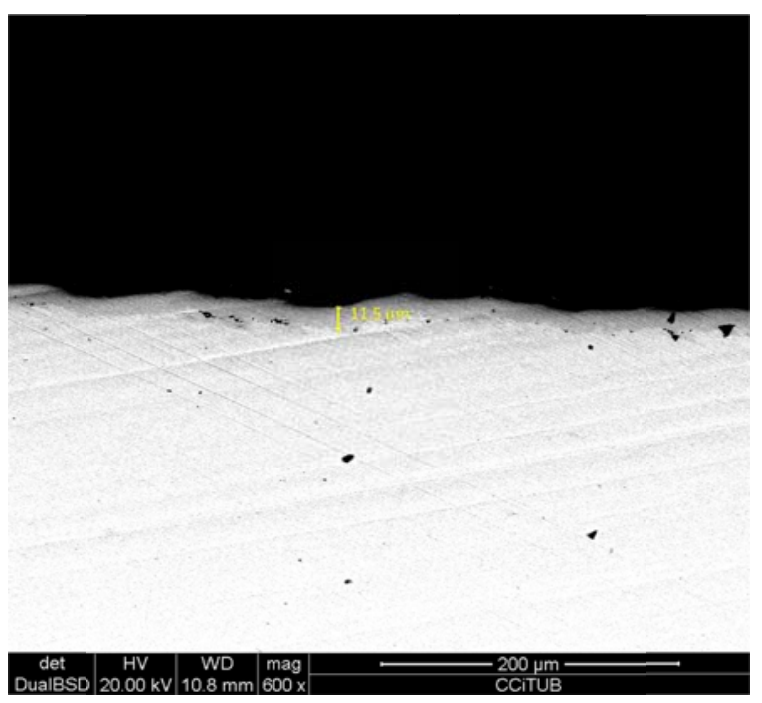

Specimen 2

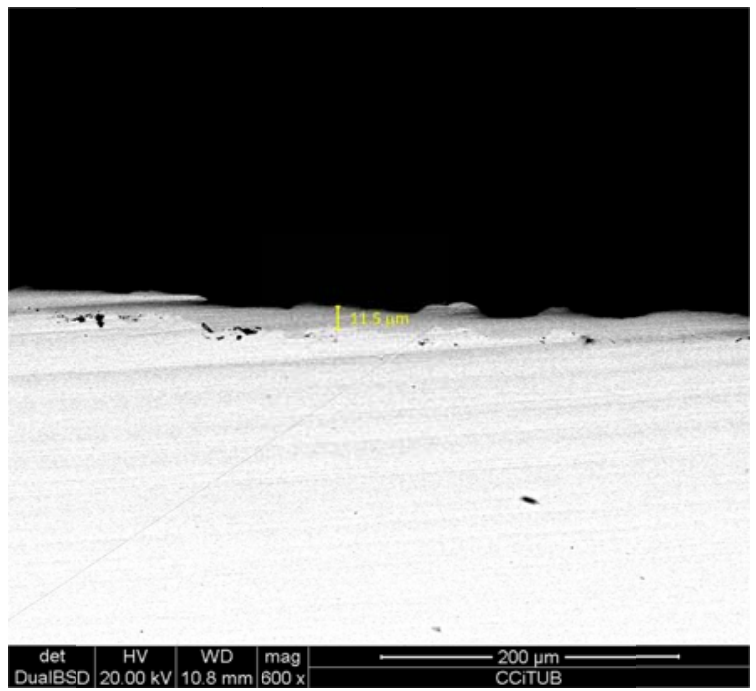

Specimen 1

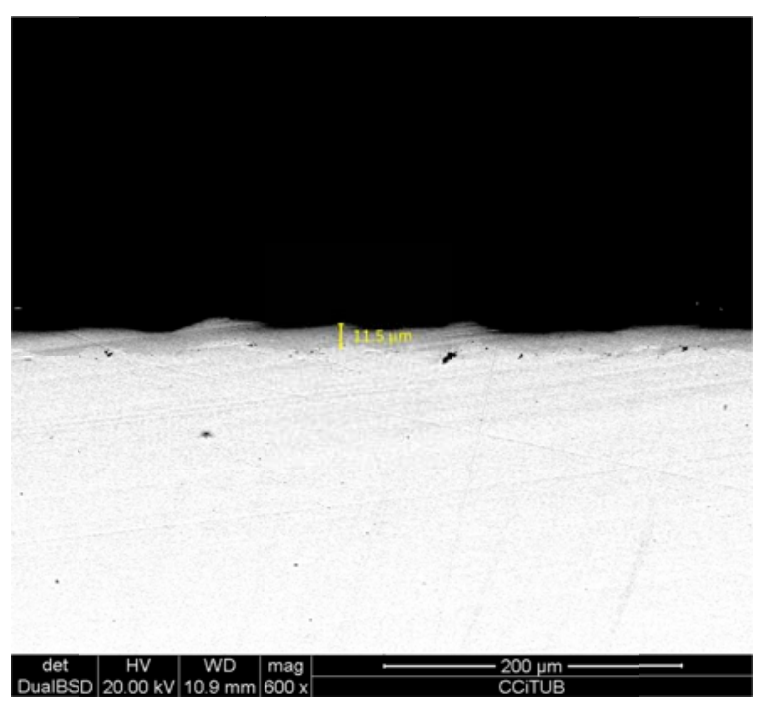

Specimen 3 (with anticorrosive spray) 


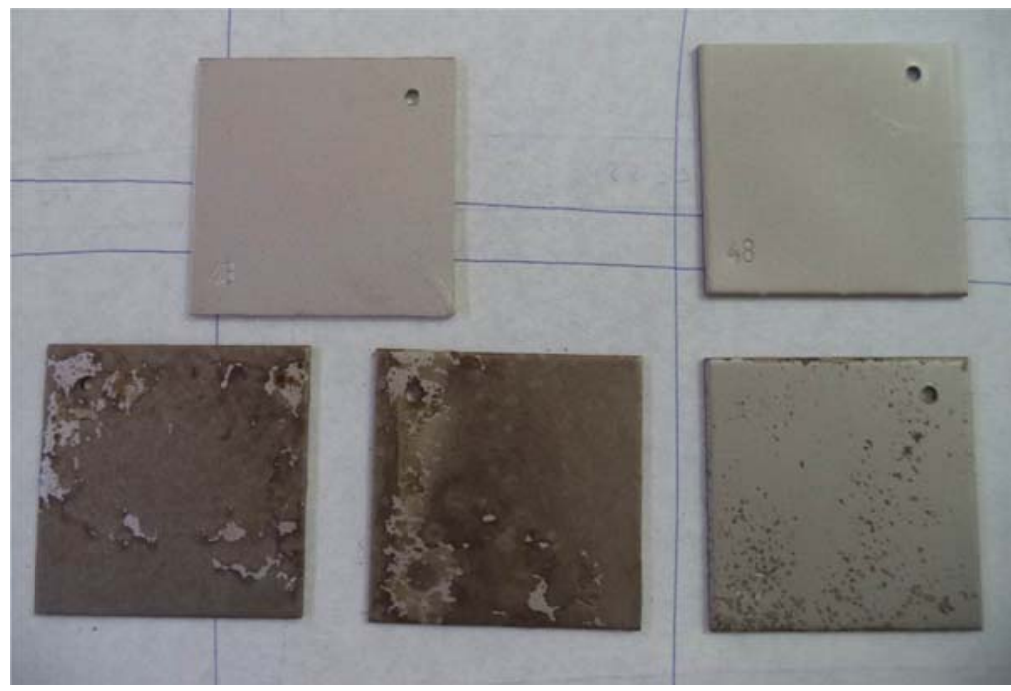

Figure 8. Copper specimens coated with Ni electroless coating. First two top are reference without spray and reference with anticorrosive spray. Bottom, three tested specimens, first two without spray, and the third with spray.

340 Figure 9 shows the SEM images captured for each specimen tested under vacuum 341 corrosion test and one reference. The images show the cross section of the specimens under study where halar ${ }^{\circledR}$ coating is shown in the upper side.

344 SEM images revealed that the coating size is exactly the same (around $150 \mu \mathrm{m}$ ) as it is observed in Figure 9. Since neither paths nor holes produced from corrosive products from the TCM are observed, this coating is recommended to be used when in contact with $\mathrm{Na}_{2} \mathrm{~S} / \mathrm{H}_{2} \mathrm{O}$ pair. 


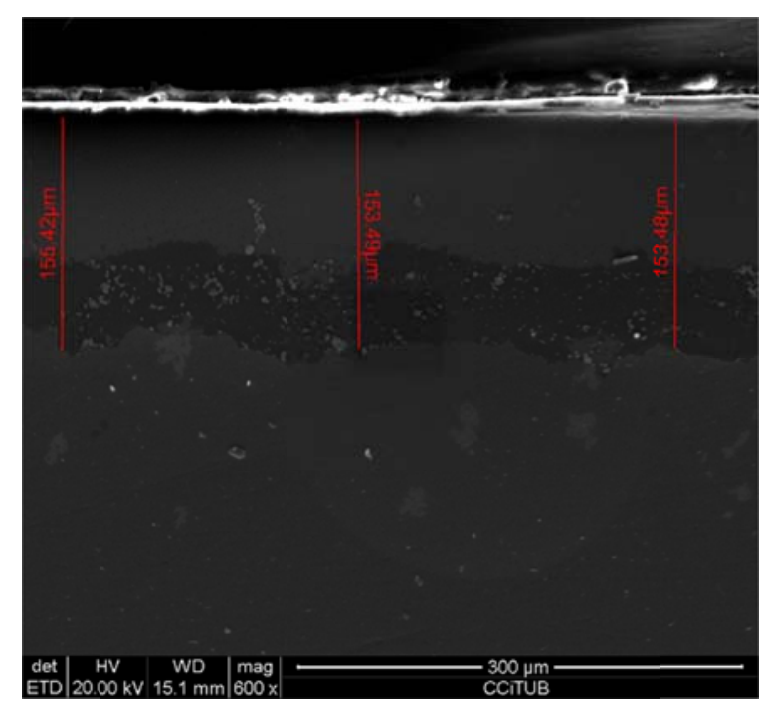

Reference

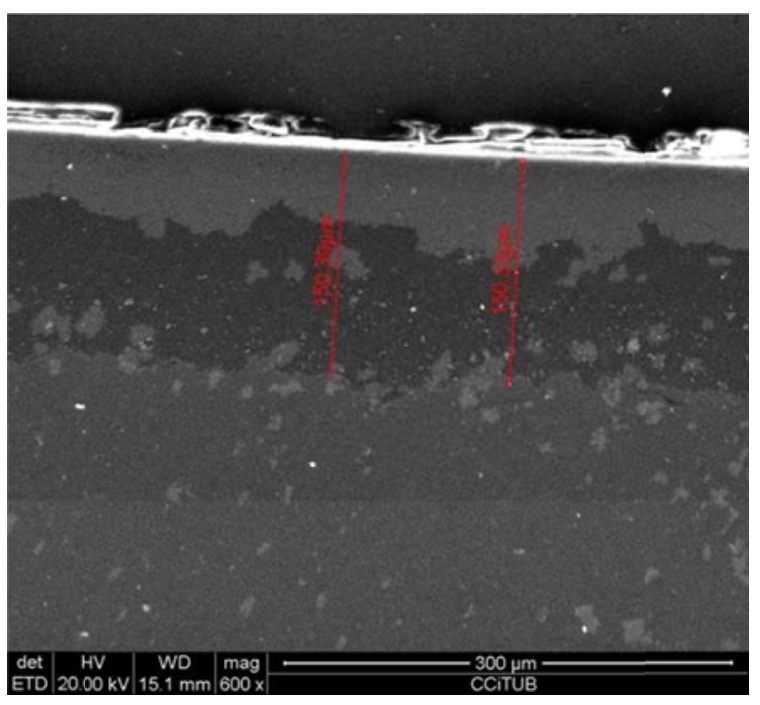

Specimen 2

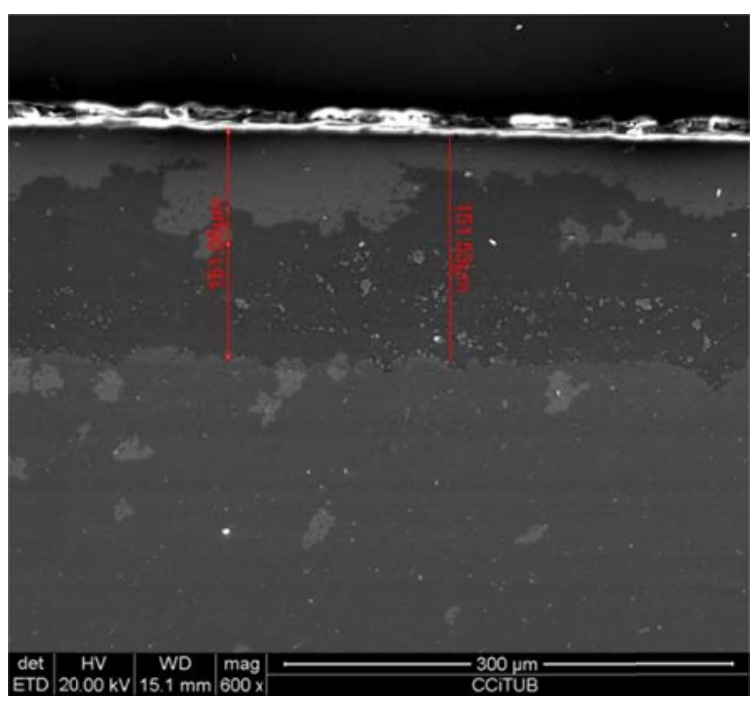

Specimen 1

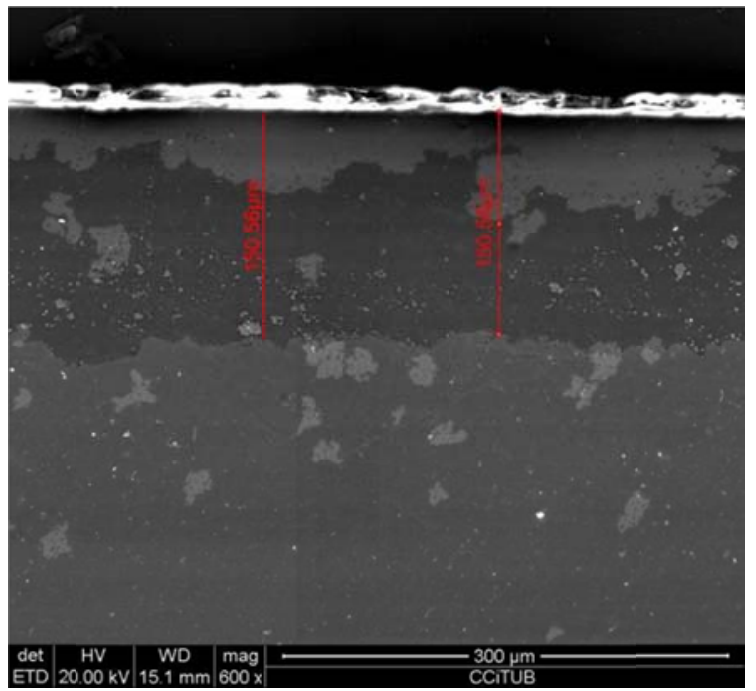

Specimen 3

Figure 9. Aluminum specimens coated with halar.

\section{D) Aluminium coated with electroless nickel}

Results of SEM images of aluminium specimens coated with nickel can be seen in Figure 10. Nickel coating shows a non-flat surface which is in contact with the metal. This fact makes difficult the comparison of the coating thickness. Nevertheless, it can be observed that no corrosion sign is seen since any degradation of the coating, neither inner paths are formed. When specimens are observed visually, as Figure 11, it can be seen that surface is damaged. Therefore, this coating is damaged by $\mathrm{Na}_{2} \mathrm{~S}$ reaction only at surface level. 


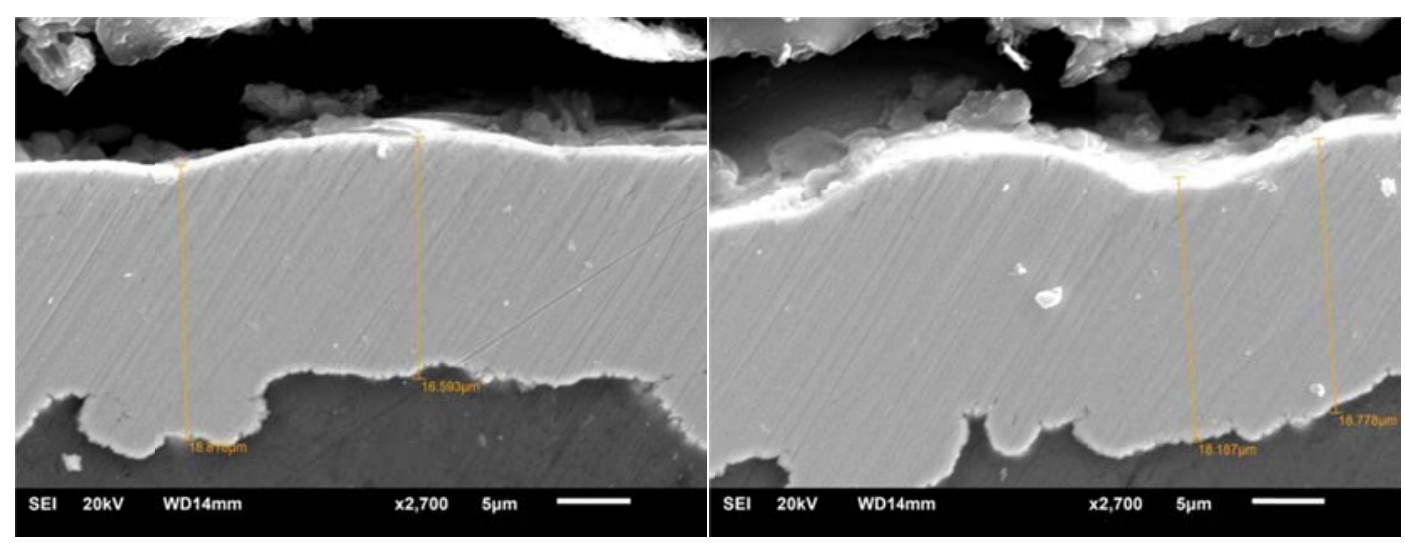

Reference

Specimen 1

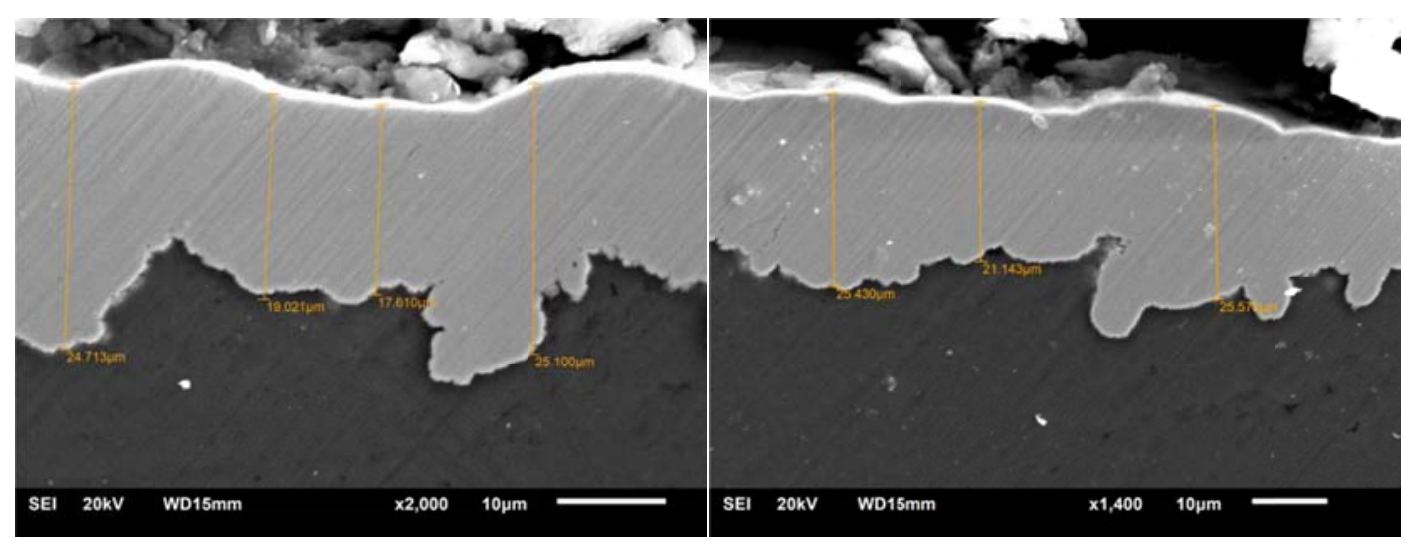

Specimen 2

Specimeln 3

Figure 10. Aluminium specimens coated with Ni electroless coating, SEM.

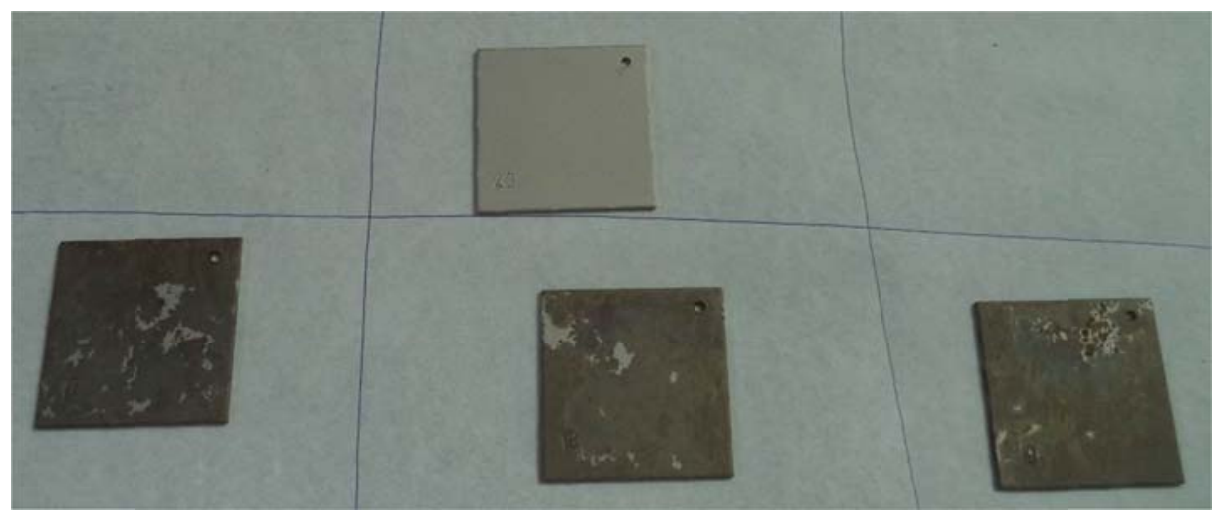

Figure 11. Aluminium specimens coated with Ni electroless coating. On the top, the reference, on the bottom, the three tested specimens.

\section{3 $\mathrm{Na}_{2} \mathrm{~S}$ XRD after corrosion vacuum test}

368 X-ray diffraction (XRD) analysis was performed to the TCM after the corrosion vacuum 369 test. This technique shows the crystalline phases that composed the samples.

370 Therefore, the XRD spectrum identifies the crystalline sample components. However, it 371 does not discern the main component, neither quantifies each detected substance. 
Here, the aim is to corroborate that the reaction from the nonahydrate to the penthydrate has taken place when performing the vacuum tests. This would imply the appearance of the pentahydrate characteristic peaks in the XRD results.

The XRD spectrum shows that there are three main crystalline substances in this sample: $\mathrm{Na}_{2} \mathrm{~S} \cdot 5 \mathrm{H}_{2} \mathrm{O}, \mathrm{Na}_{2} \mathrm{~S} \cdot 9 \mathrm{H}_{2} \mathrm{O}$ and $\mathrm{Na}_{2} \mathrm{SO}_{3} \cdot \mathrm{Na}_{2} \mathrm{SO}_{3}$ appears in the composition due to the atmosphere contact during the sample preparation and extraction in the corrosion reactors.

\section{Conclusions}

A setup composed by a $5 \mathrm{~L}$ glass jacketed reactor, evaporator, and a vacuum pump has been developed at lab scale to test corrosion of thermochemical materials under different atmospheres and a wide range of pressure and temperature. A new methodology to perform these tests has been designed, explained in detailed, tested and validated.

One TCM pair, $\mathrm{Na}_{2} \mathrm{~S} / \mathrm{H}_{2} \mathrm{O}$, has been selected to perform vacuum corrosion tests at 13 mbar and $32.5^{\circ} \mathrm{C}$ when in contact with commonly used metals and coated metals used to build up thermochemical reactors.

From the screening corrosion vacuum tests performed with the TCM reaction from the nonahydrate to the pentahydrate sodium sulphide it can be concluded that copper is not recommended to contain $\mathrm{Na}_{2} \mathrm{~S} / \mathrm{H}_{2} \mathrm{O}$, neither in open nor in close configurations, besides that in closed and vacuum corrosion rate value is reduced by 30 times. In the case of stainless steel 316 results show that is recommended for long term service.

Two coatings have been tested when applied onto copper and aluminium, two metals highly used for the manufacturing of TCM heat exchangers. Halar coating results make it a potential candidate to be selected to protect heat exchangers/reactor that may contain $\mathrm{Na}_{2} \mathrm{~S} / \mathrm{H}_{2} \mathrm{O}$ pair for thermochemical energy storage. Electroless nickel shows no corrosion when observing SEM images, but it is visually damaged at surface level after the corrosion test. When a finishing spray is applied it improves the material resistance against corrosion.

Moreover, further tests are suggested to carry out to ensure that the materials which do not present corrosion can resist for longer periods. Also, heat transfer coefficient should be measured with the selected metal or coated metal to ensure that heat transfer is not the limiting step in the reactor. 
402 The research leading to these results has received funding from the European 403 Commission Seventh Framework Programme (FP/2007-2013) under grant agreement 404 No ENER/FP7/295983 (MERITS). Aran Solé would like to thank the Departament 405 d'Universitats, Recerca i Societat de la Informació de la Generalitat de Catalunya for 406 her research fellowship. The work is partially funded by the Spanish government 407 (ENE2011-22722). The authors would like to thank the Catalan Government for the 408 quality accreditation given to the research group GREA (2014 SGR 123).

409

\section{References}

411 [1] International Energy Agency, Technology Roadmap, Energy Storage, 2014.

412 [2] C.W. Chan, J. Ling-Chin, A.P. Roskilly. Reprint of "A review of chemical heat pump, 413 thermodynamic cycles and thermal energy storage technologies of low grade heat 414 utilisation". Appl. Therm. Eng. 53 (2013) 160-176.

415 [3] M.A. Rosen, Energy Storage, Nova Science Publishers, Hauppauge, New York, 4162012.

417 [4] Y. Aristov, D.M. Chalaev, B. Dawoud, L.I. Heifets, O.S. Popel, G. Restuccia, 418 Simulation and design of a solar driven thermochemical refrigerator using new 419 chemisorbents, Chem. Eng. J. 134, 1, (2007) 58-65.

420 [5] https://www.nace.org/Publications/Cost-of-Corrosion-Study/ (last accessed $42106 / 06 / 15)$

422 [6] E. Opila, High temperature materials corrosion challenges for energy conversion 423 technologies, Electrochemical Society Interface 22 (2013) 69-73.

424 [7] A. Solé, L. Miró, C. Barreneche, I. Martorell, L. F. Cabeza, Corrosion of metals and 425 salt hydrates used for thermochemical energy storage, Renew. Energ. 75 (2015) 519426523.

427 [8] A. Solé, I. Martorell, L. F. Cabeza, State of the art on gas-solid thermochemical 428 energy storage systems and reactors for building applications, Renew. Sust. Energ. 429 Rev. 47 (2015) 386-398. 
430 [9] V.M. Van Essen, J. C. Gores, L.P.J. Bleijendaal, H.A. Zondag, R. Schuitema, M. 431 Bakker, W.G.J. van Helden, Characterization of salt hydrates for compact seasonal 432 thermochemical storage, 3rd International Conference of Energy Sustainability 2009, 433 San Francisco, USA, 19-23 July 2009.

434 [10] X. Fontanet, Estudio del $\mathrm{Na}_{2} \mathrm{~S}$ como material de almacenamiento termoquímico. 435 University of Barcelona. Graduate Thesis. 2013.

436 [11] A. Frankel, G. Grundmeier, H. McMurray, T. Shinohara, Coatings for corrosion 437 protection, The electrochemical society, New Jersey, US, 2010.

438 [12] A-J. de Jong, R. Stevens, C. Rentrop, C. Hoegaerts, Coating development for 439 thermochemical heat storage reactors, International Conference on Solar Heating and 440 Cooling for Buildings and Industry, SHC 2014, Beijin, China, 2014.

441 [13] S.L. Shawla, R.K. Gupta, Material selection for corrosion control, ASM 442 International, US, 2010.

443 [14] A. Forsgren, Corrosion Control through Organic Coatings, CRC Press, Taylor and 444 Francis Group, US, 2006.

445 [15] J. R. Davis, Corrosion: Understanding the Basics, ASM International, US, 2000.

446 [16] ASTM G1-03, Standard for Preparing, Cleaning, and Evaluating Corrosion Test 447 Specimens. 2003.

448 [17] K. E. N'Tsoukpoe, T. Schmidt, H. U. Rammelberg, B. A. Watts, W.K.L. Ruck, A 449 systematic multi-step screening of numerous salt hydrates for low temperature 450 thermochemical energy storage, Appl. Energ. 124 (2014) 1-16.

451 [18] A-J. de Jong, F. Trausel, C. Finck, L. Van Vilet, R. Cuypers, Thermochemical heat 452 storage - system design issues, International Conference on Solar Heating and 453 Cooling for Buildings and Industry, SHC2013, Freiburg (Germany), Energy Procedia 48 454 (2014) 309-319.

455 [19] www.solvaychemicals.us (last accessed 06/06/15)

456 [20] R. De Boer, W.G. Haije, J.B.J. Veldhuis, Determination of structural, 457 thermodynamic and phase properties in the $\mathrm{Na}_{2} \mathrm{~S}-\mathrm{H}_{2} \mathrm{O}$ system for application in 458 chemical heat pump, Thermochim. Acta 395 (2003) 3-19.

459 [21] D. L. Perry, Handbook of inorganic compounds, second ed., CRC Press, 2011. 
460 [22] www.alfa.com/msds/british/11664.pdf (last accessed 06/06/2015)

461 [23] M. Kutz, Applied Plastics Engineering Handbook: Processing and Materials, Hand 462 Book Series, Elsevier, US, 2011.

463 [24] K.L. Choy, Chemical vapour deposition of coatings, Prog. Mater. Sci. 48, 2 (2003) $464 \quad 57-170$.

465 [25] ASTM B 733 - 97, Standard Specification for Autocatalytic (Electroless) Nickel466 Phosphorus Coatings on Metal, 1997.

467 [26] V.S. Sastri, E. Ghal, M. Elboujdaini, Corrosion, prevention and protection. Practical 468 solutions, John Wiley \& Sons, Chichester, UK, 2007. 